NASA/CR-1998-207403

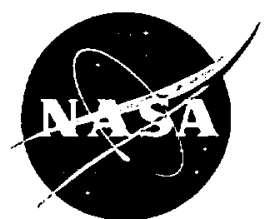

\title{
PSP Measurement of Stator Vane Surface Pressures in a High Speed Fan
}

Jan Lepicovsky

NYMA, Inc., Brook Park, Ohio

Prepared for the

43rd Gas Turbine and Aeroengine Congress

sponsored by the American Society of Mechanical Engineers

Stockholm, Sweden, June 2-5, 1998

Prepared under Contract NAS3-27186

National Aeronautics and

Space Administration

Lewis Research Center 


\section{Acknowledgments}

The author is grateful to Dr. L.J. Bober of the NASA LeRC Compressor Branch for his continuing support. T.J. Bencic of NASA LeRC was instrumental in the PSP data acquisition. The help of E.P. Braunscheidel and R.J. Bruckner, both of NASA LeRC, is also particularly acknowledged.

Available from

NASA Center for Aerospace Information 7121 Standard Drive Hanover, MD 21076

Price Code: A03
National Technical Information Service 5287 Port Royal Road Springfield, VA 22100 Price Code: A03 


\title{
PSP MEASUREMENT OF STATOR VANE SURFACE PRESSURES IN A HIGH SPEED FAN
}

\author{
Jan Lepicovsky \\ NYMA, Inc. \\ NASA Lewis Research Center Group, \\ Brook Park, OH 44142
}

\begin{abstract}
This paper presents measurements of static pressures on the stator vane suction side of a high-speed single stage fan using the technique of pressure sensitive paint (PSP). The paper illustrates development in application of the relatively new experimental technique to the complex environment of internal flows in turbomachines. First, there is a short explanation of the physics of the PSP technique and a discussion of calibration methods for pressure sensitive paint in the turbomachinery environment. A description of the image conversion process follows. The recorded image of the stator vane pressure field is skewed due to the limited optical access and must be converted to the meridional plane projection for comparison with analytical predictions. The experimental results for seven operating conditions along an off-design rotational speed line are shown in a concise form, including performance map points, midspan static tap pressure distributions, and vane suction side pressure fields. Then, a comparison between static tap and pressure sensitive paint data is discussed. Finally, the paper lists shortcomings of the pressure sensitive paint technology and lessons learned in this high-speed fan application.
\end{abstract}

\section{Nomenclature}

Symbols:

$b_{M} \quad[\mathrm{~mm}]$ vane axial midspan chord

1 [1] signal intensity (levels of gray)

$L_{A V}[1] \quad$ average luminescence (levels of gray)

$\begin{array}{lll}L_{x} & {[1]} & \text { local (pixel) luminescence (levels of gray) } \\ P_{E x} & {[\mathrm{kPa}]} & \text { fan exit total pressure } \\ P_{P T} & {[\mathrm{kPa}]} & \text { inlet plenum total pressure } \\ p_{x} & {[\mathrm{kPa}]} & \text { local static pressure } \\ m & {\left[\mathrm{~kg} \cdot \mathrm{s}^{-1}\right]} & \text { mass flow } \\ m_{\mathrm{CH}} & {\left[\mathrm{kg} \cdot \mathrm{s}^{-1}\right]} & \text { mass flow at choke condition } \\ x & {[\mathrm{~mm}]} & \text { axial distance }\end{array}$

Abbreviations:

CCD charge-coupled device

PSP pressure sensitive paint

\section{Background}

The design of future turbine engine components and predictions of their performance will, to a great extent, depend on sophisticated computational fluid dynamics codes. However, before the complex computer codes can be used successfully for production designs, they must be thoroughly verified and their reliability and accuracy tested. Consequently, modern experimental techniques for turbomachinery application must refocus from overall performance testing to the description and understanding of details of flow physics inside a machine, particularly at off-design conditions. The experimental data needed for code verification must be comprehensive, illustrating trends under a variety of operating conditions, and not showing solely flow parameters at individual point locations for specific operating regimes. Current conventional experimental techniques with intrusive probes do not fully suffice for 
that purpose in the turbomachinery environment. Nonintrusive experimental techniques supplying area (field) data, rather than discrete point values only, should be adopted for measurement in the turbomachinery environment. Pressure sensitive paint (PSP) technology is a promising technique for that objective. Although relatively new, the PSP technique is already well established in external aerodynamics and wind tunnel measurements (Morris et al., 1992, Crites, 1993, and Torgerson et al., 1996). In confined flows, turbomachinery, and elevated temperature applications, however, there are still problems (Lepicovsky, 1996). One of the first measurements on the first stage rotor blades of a high speed axial compressor was carried out by Liu et al. (1997); however, no measurement was attempted on stator vanes. This paper describes NASA experience with the application of PSP to stator vanes of a high-speed fan; it is believed that this is the first application of PSP to measurements in the stator of a high-speed fan.

\section{Purpose of the Study}

The study had two main objectives. The first objective was to gain experience with PSP in the environment of modern high-speed fans. The second objective was to record the changes in the pressure field on the suction side of a stator vane as the operational point of the fan was moved from stall to choke conditions at a constant rotational speed. Additional goals were to develop software to convert PSP data recorded under skewed observation angles to the meridional plane view platform for comparison with computational predictions, and to assess the reliability of the PSP layers on stator vanes under realistic operational conditions.

\section{Experimental Technique of Pressure Sensitive Paint}

PSP techniques are based on oxygen quenched photoluminescence. Photoluminescence is the property of some compounds to emit light after being illuminated by a suitable light source. For certain compounds the intensity of the emitted light depends on the oxygen partial pressure; it decreases with an increasing oxygen pressure; therefore, the emitted light intensity directly relates to the ambient pressure of a surrounding gas containing oxygen. McDonnell-Douglas paint (MDA), used for this investigation (Crites, 1993), requires an excitation illumination in the blue region of the optical spectrum and returns a signal in the yellow wavelength range. To detect and record emitted light, containing the pressure information, a CCD imager (camera) was used (Bencic, 1995).

A test setup of a PSP application for turbomachinery testing is shown in Fig. 1. The CCD camera and two blue-light halogen lamps are in the foreground (camera in middle; halogen lamps are inside ribbed cooling jackets). The camera faces an access window over a single stage fan stator. Three stator vanes are visible in the access window. The suction side of the middle vane (the upper surface) was painted for testing. The air in the fan flows from right to left.

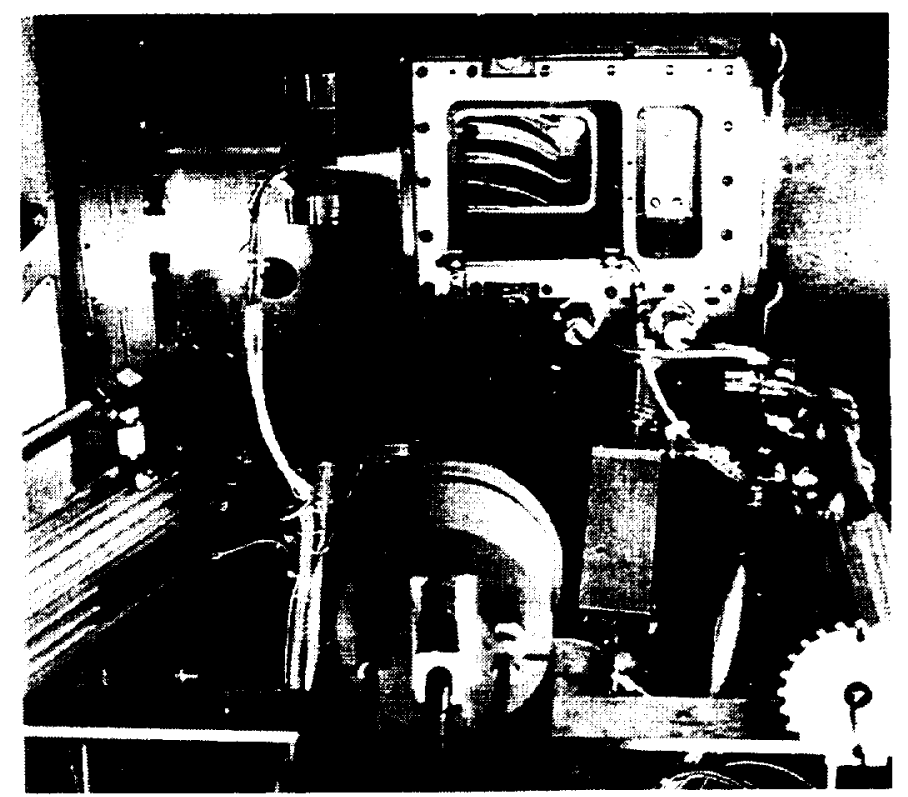

Figure 1. PSP setup for turbomachinery application.

Due to optical access limitations, the CCD camera records a skewed two-dimensional image of the stator vane. An example for the vane suction surface is shown in Fig. 2. The image of luminescence intensity distribution, recorded by the CCD camera, is originally black and white. The result in Fig. 2 shows a computer color-coded distribution of paint luminescence intensity. The scale is normalized by the average luminescence over the test area $\left(L_{A V}\right)$. Luminescence is expressed in terms of gray levels and is therefore dimensionless; the numerical values are relative. The result in Fig. 2 must be modified in two ways to allow for direct comparison with analytical data. First, emitted light intensity must be converted to pressure units using a PSP calibration procedure; second, the skewed view image of the stator vane must be converted to the meridional projection view that is customary in compressor designs. 


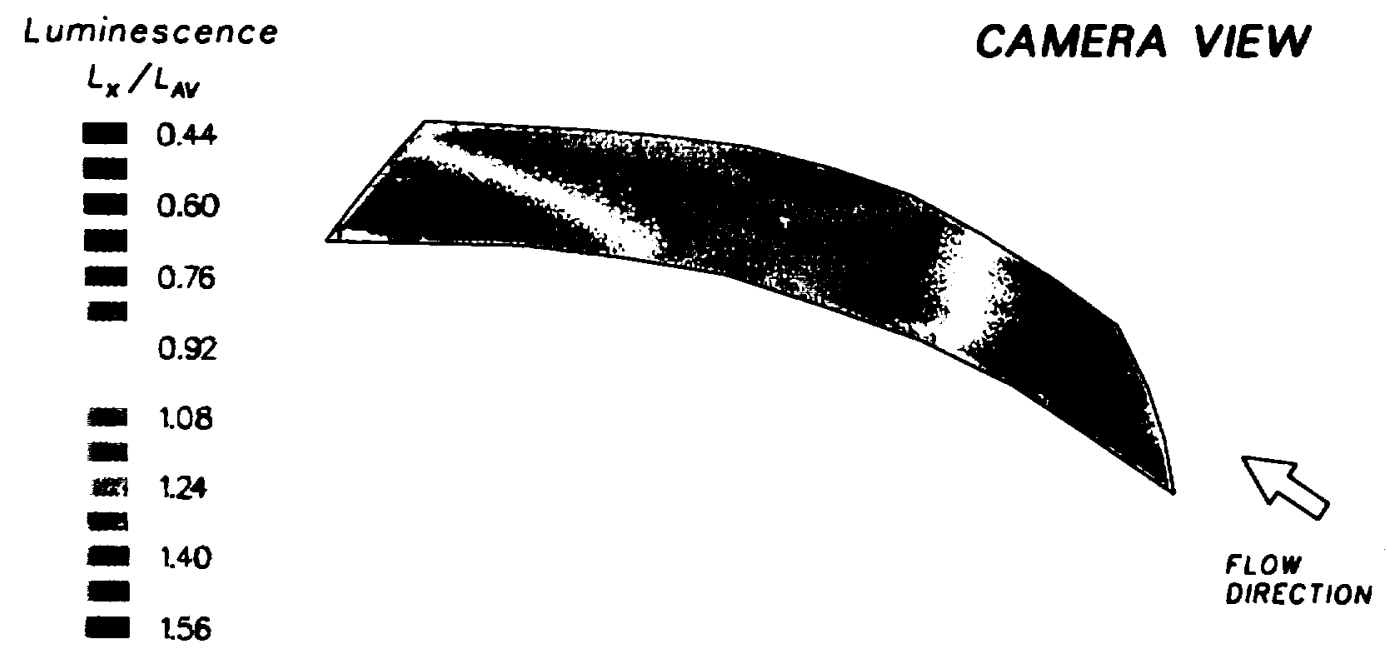

Figure 2. Camera image of vane suction surface painted with PSP.

\section{Calibration of Pressure Sensitive Paint}

The basis of the PSP technique is the inverse proportionality between the intensity of the emitted light signal and the partial pressure of oxygen permeating the paint coating. The relation between the signal intensity $(/)$ and the pressure value $(p)$ is captured by the SternVolmer equation

$$
I_{R} / I=A+B *\left(p / p_{R}\right)
$$

where constants $A$ and $B$ are determined by the calibration procedure and the subscript $R$ indicates reference or "flow off" values (Crites 1993 and Bencic 1995). The calibration coefficients are unique for each PSP compound (Torgerson et al., 1996). Unfortunately, the emitted light intensity does not depend solely on oxygen partial pressure but is also a strong function of other factors such as illumination intensity, sensing direction, paint layer thickness, and surface temperature. A methodology was developed for wind tunnel (external aerodynamics) applications that minimizes the effects of all factors except pressure changes (Morris et al., 1992, Crites, 1993, Morris et al., 1993, and Bencic, 1995). In this approach, two images of the tested surface (emitted light distributions) are acquired; one "flow off" reference image is taken for the known uniform pressure distribution over the tested surface (reference values $I_{R}$ and $p_{R}$ ), and a second "flow on" run image for the unknown pressure distribution under the desired test conditions (test values $($ and $p)$. This methodology, however, assumes very small differences in surface temperatures between the reference and run images.
In high-speed turbomachinery applications, there are unavoidable and noticeable differences between the surface temperatures for the reference and test conditions because the reference image must be taken when the machine is not operating. If the temperature distribution on the tested surface at run conditions is known, a correction to the calculated pressure values can be applied as suggested by Morris et al. (1992), and Woodmansee and Dutton (1997). Moderate temperatures (up to $50 \mathrm{~K}$ above ambient) do not affect the linearity of PSP response (Liu et al., 1997) but do increase the noise of the signal (Lepicovsky et al., 1997). Because in the present investigation the temperature distribution on the vane surface was not known, the corrections for temperature effects could not be applied. Therefore, the universal calibration coefficients could not be utilized and the in-situ calibration method was used instead.

The in-situ calibration method also uses the method of two images but instead of relying on the predetermined proportionality factors for the given PSP compound, it uses several known pressure values within the measurement area to calculate the linear fit calibration coefficients independently for each test condition (constants $A$ and $B$ ). Calibration pressures on the vane suction surface were determined from nine static taps along a straight line approximately at mid span of a vane. The instrumented vane is shown in Fig. 3. The static taps were circular with a diameter of $0.4 \mathrm{~mm}$. Ideally, the taps should be located on the painted surface, but in the present arrangement the 

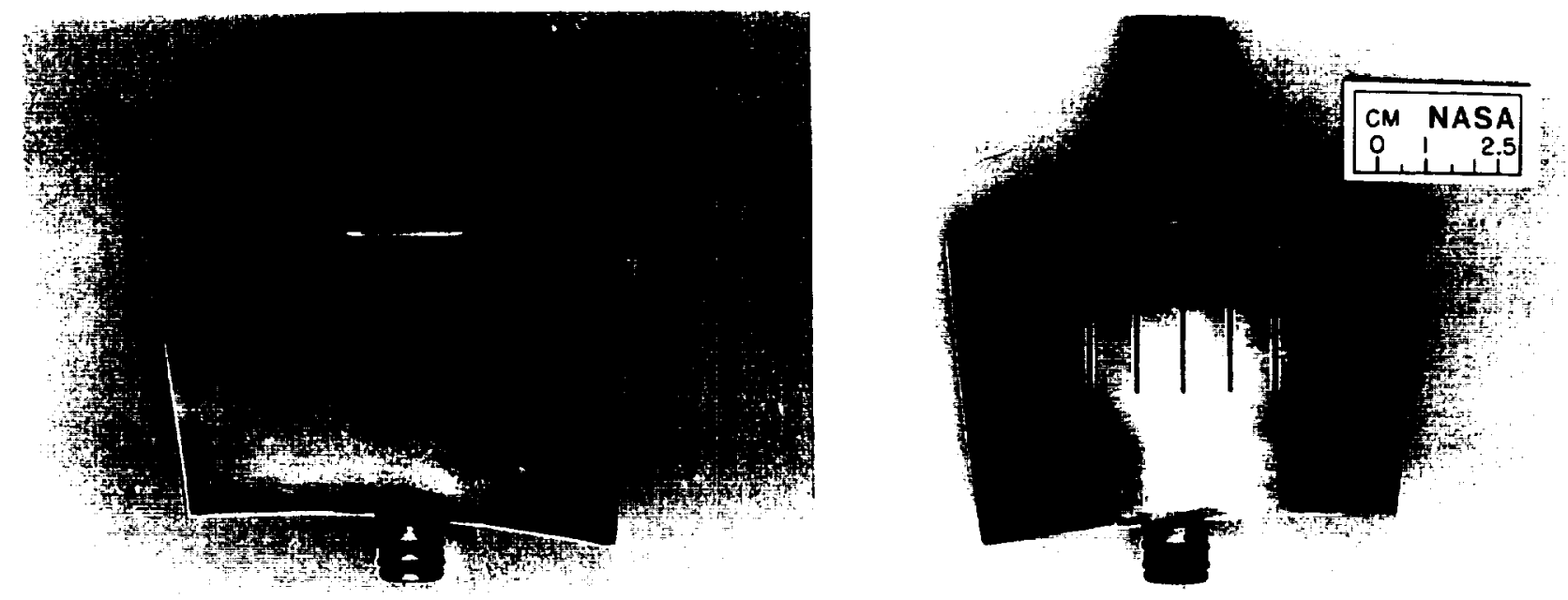

Figure 3. Vane instrumented with nine static taps.

stator vane channels instrumented with static taps were different from those painted with PSP. Therefore, in this case the reliability of the in-situ calibration relies on the assumption of identical flow and pressure fields in the channels involved. It is believed that for most of the test conditions the pressure fields in both channels were nearly identical; however, for the near choke condition there may be significant differences, so the data must be assessed cautiously.

The individual calibration curves (determined using a linear least squares fit) for each run data point were used to convert the PSP signal into pressure values. Then, differences between static pressure tap data and corresponding PSP data values (calibration residuals) were calculated. The overall estimated PSP data error band was computed as population standard deviations of the PSP calibration residuals normalized by the inlet plenum total pressure and the normalized error band of the static tap data measurements. The resulting normalized error band of the PSP data for the data set presented is $\pm 3.9 \%$ of the inlet total pressure.

\section{Image Geometry Transformation}

A convenient way to view vane surface pressure distributions is to project them onto the meridional plane. However, due to optical access limitations, the recorded image of a stator vane surface is skewed (Fig. 2). Therefore, an image transformation algorithm was devised to convert skewed-viewed surface pressure field to meridional plane projection. The problem of skewed view is less severe for the front view of the first stage rotor as in the case reported by Liu at al. (1997), but for measurements in the stator cascade it represents a significant complication.

The transformation procedure mathematically manipulates the recorded image to create a meridional projection of the vane tested. The geometry of the recorded vane image depends on the camera position. Therefore, for a rigorous transformation procedure, the mutual positions of the recording camera and the tested vane must be known. In the busy environment of a compressor test cell, it is not always practical and efficient to keep track of the exact camera position with respect to the access window (the camera position was changed frequently to minimize or eliminate light reflections from the curved window glass; also servicing the fan instrumentation during tests required removing the camera). Consequently, an approximate transformation procedure was developed that does not require recording the camera positions. The procedure is limited to mildly curved blade surfaces, and to improve the accuracy of the transformation procedure the camera should always be located in a position that minimizes the optical distortion of the recorded image.

The process of image transformation is outlined in Fig. 4. The procedure starts in the camera plane (upper left corner). Here, the camera pixel grid ( 512 by 512 ) is indicated with the captured contour of the vane suction side. It must be stressed here that the contour image position is "free to drift" with respect to the camera grid (which means the camera position may vary). A particular contour position depends on the vane position, camera position, and the camera objective. For a given image, however, the vane 
contour can be retrieved in pixel coordinates of the camera grid.

The picture in the image plane llower left corner of Fig. 4) shows the vane cell grid that is anchored to the vane contour. This grid was calculated using the contour coordinates in pixels from the camera plane. In this particular case the cell grid size (height by chordwise length) is selected as 80 by 360 in order to approximate the pixel size of the camera grid. The cell corner coordinates are calculated in both the camera pixel coordinate system and the vane grid coordinate system. The dual status of the cell coordinates allows mapping of pressure values from the camera pixel locations to the vane cell grid. The mapping mechanism, shown in Figs. 5 and 6 , is as follows. For a given cell in the image plane llabeled I CELL in Figs. 5 and 6), the corresponding pixel coordinates are determined and the cell is "projected" from the image plane onto the pixel grid of the camera plane (Fig. 5). After that, an area of 5 by 5 pixels around the projected cell in the camera plane is checked, and pressure values for all pixels that fall in the cell area are integrated to determine an average pressure value that is assigned to the selected grid cell as indicated in Fig. 6 . The procedure is repeated for all cells in the image plane.

The next step is to calculate the vane cell grid in the meridional plane using a procedure similar to that just described for the image plane; however, this time the vane contour physical geometry is used instead of the camera plane image contour (upper right corner in Fig. 4). To display the resulting pressure field with comparable spatial resolutions in the height and chordwise directions, a meridional plane (height by chordwise lengthl grid size of 80 by 120 was selected. Then. the image plane data in the chordwise direction were grouped (three cells in a group), averaged (reduction from 360 to 120 cells), and plotted in reversed order in the meridional plane grid. The reversed order of data plotting inverts the flow direction and vane orientation in these two planes. The solid triangles in the image and meridional plane contours in Fig. 4 indicate the tip/leading-edge corner of the vane.

Finally, Fig. 7 shows the pressure field map after the image geometry transformation in the meridional plane projection, with flow from left to right. Also, the luminescence intensity has been converted to pressure values using the PSP calibration procedure. As already stated, the luminescence intensity is inversely proportional to the surrounding pressure, so the luminescence and pressure scales are inverted to keep the same color coding for luminescence and pressure field maps (compare Figs. 2 and 7). The involved image processing effects the resulting spatial accuracy. The contour shape of the transformed image is within $\pm 2.0 \%$ of the sizes of the original hardware.

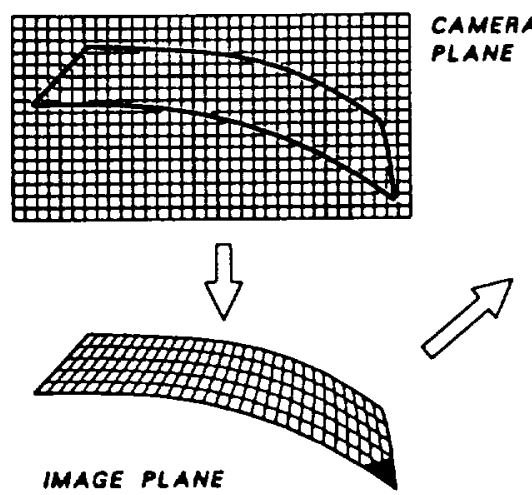

mEAIDIONAL PLANE

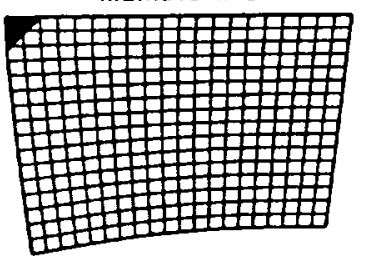

Figure 4. Process of image conversion.

LOCAL SEAACH DOMAIN $6 \times 6$ PIXELS

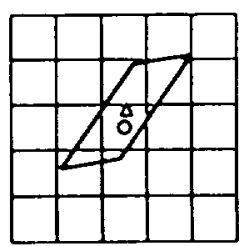

A LCELL CENTER - neAaEst pixel centea

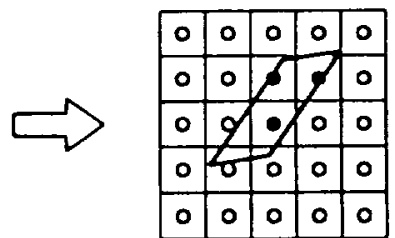

- pixel centeas outside l_cell - pixel centeas wsioe locell
Figure 5. Pixel search algorithm.

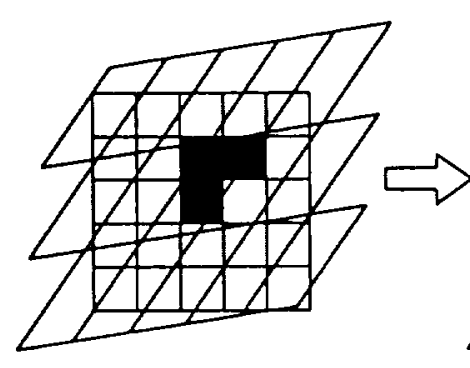

PIXEL DOMAIN

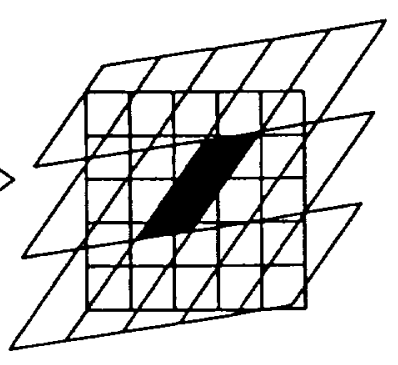

LCELL DOMAIN
Figure 6. Process of domain transformation. 


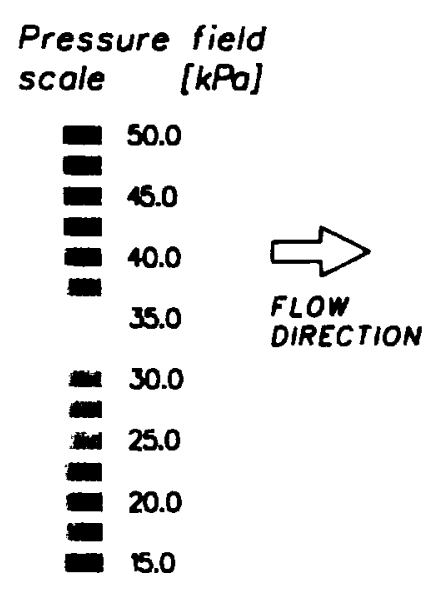

MERIDIONAL PLANE

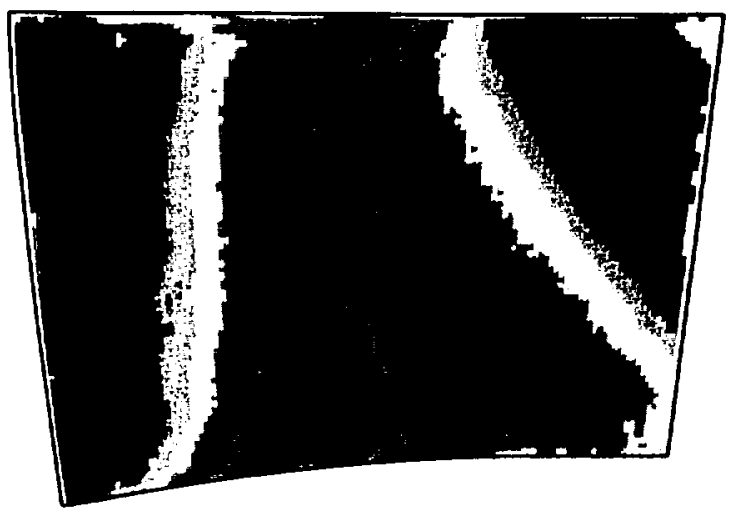

Figure 7. Meridional plane suction-side vane-surface pressure field.

\section{Experimental Results}

The experimental results for seven operating conditions of a high-speed single-stage fan for the same off-design rotational speed are shown in concise form in Fig. 8. Individual subsets in this figure, each for a separate operating condition, are labeled Test Point $A$ through $G$. Each subset is composed of three diagrams arranged vertically. The top diagram shows the speed line of the fan performance map (stage pressure ratio versus mass flow) for which the PSP tests were carried out. The speed line is shown as a double line; the large solid dot on it indicates the specific operating point for the given subset. The stage pressure ratio is expressed as the ratio of exit and inlet total pressures. The mass flow rate is nondimensionalized by the mass flow rate at the stage choke condition.

The middle diagram shows the static pressure distribution on the vane suction side as measured by nine static taps located along a straight line approximately at mid span of the vane (see Fig. 3). The vane static pressure ratio represents the tap static pressure divided by the inlet total pressure. Finally, the bottom diagram shows the pressure field map on the vane suction side as determined by the PSP technique. The pressure levels are color coded in a rainbow convention (violet is the low pressure level and red represents the high level). Again, the pressure levels are nondimensionalized by the inlet total pressure. The black dots in the pressure field maps indicate locations of the static taps on the vane suction surface.

Static Tap Pressure Distributions. As the operating point is varied along the speed line from the near stall conditions (Test Point $A$, Fig.8) to a condition beyond choke (Test Point G, Fig. 8 ), the midspan static pressure distributions change dramatically. The observed changes are similar to the pressure distribution changes in a convergent-divergent channel for a constant inlet pressure and decreasing exit (back) pressure. As the back pressure drops, the mass flow rate increases, and pressure distribution exhibits a minimum at the throat region until choking occurs, after which, for further decrease of the back pressure, the minimum pressure occurs just ahead of a shock in the divergent portion of the channel. Based on the ratio of the fan total pressure and local static pressure on the vane suction surface, the maximum local Mach number in the vane channel for the condition of Test Point $E$ rises to approximately 0.89 at the channel throat. For the test conditions of Test Points $F$ and $G$, the flow is supersonic past the channel throat. For Test Point $F$ the flow Mach number reaches up to 1.18 and then a shock slows it to a subsonic exit. For the operating condition of Test Point $G$ the flow is supersonic back to the aft end of the stator channel (Mach number 1.44).

Static Pressure Field Maps. For the operating point close to fan stall (Test Point A, Fig. 8), the vane suction-side static-pressure field is nearly uniform, with a slight trend of increasing pressure in the radial direction (hub to tip). The pressure at the blade tip reaches a level approximately $25 \%$ above the fan inlet total pressure. As the operating point is moved away from the near stall condition, the pressure starts to drop, beginning around the hub throat region (Test Points $B$ and $C$ ). Further increases in the mass flow rate are accompanied by the formation of a region of lower pressure extending from the hub to the tip of the vane 
in the channel throat region (Test Points $D$ and $E$ ). The pressure field map for the conditions of Test Point $E$ corresponds to the situation where the flow velocity in the throat region is nearly sonic. As the operating point approaches and enters choked stator conditions, the static pressure field changes rapidly with decreases in back pressure. After the throat becomes choked, further decreases in back pressure induce the formation of a shock wave in the channel, downstream of the channel throat (Test Point $A$. The shock wave, or at least its pressure-rise imprint on the vane suction side, is straight and oriented in the radial direction. Finally, for conditions well within the fan choke regime (Test Point G) the shock wave is located just upstream of the vane channel exit. The shock wave is oriented mainly in the radial direction with some minor curvature near the hub and tip endwalls.

PSP Versus Static Tap Data. A comparison between static tap data and PSP data along the vane midspan chord is shown in Fig. 9 for four operating conditions (Test Points $A, D, E$, and $G$ of Fig. 8). The agreement is quite good with only a few exceptions. It must be pointed out here, however, that these two data sets are not completely independent -- static tap data were used to generate PSP calibration constants. The calibration constants determine the average pressure level for the given test condition, however, they do not determine the shape of the pressure distribution. Therefore, the comparison should be viewed in light of the curve shape similarity rather than in light of absolute pressure values. Also, it should be remembered that the PSP data and the static tap data were acquired in different stator channels. Small variations in the geometry between the vane channel which was tap instrumented and that which was PSP painted will result in noticeable variations in the static pressure distributions, particularly when the fan is operating near choke. This is true particularly, when the fan is operated near choke (Test Points $E, F$, and $G$ of Fig. 81, the pressure field exhibits dramatic variations for very small changes in the operating conditions. Therefore, the good agreement also indicates good similarity between the two involved channels. Second point to be made here is that the good similarity seems to confirm the assumption of small effects of flow temperature variations on the PSP results in this particular application. In summary, the overall trends of static tap and PSP data agree quite well and are within the estimated error band of $\pm 3.9 \%$ of the inlet total pressure determined from the PSP calibration.

\section{Operational Reliability of PSP}

During the experiments, several problems were encountered that affected the reliability of the PSP technique in a turbomachinery environment and must be resolved for the PSP method to become a practical tool for experimental turbomachinery research. The most serious problems were (1) a drop in paint sensitivity due to oil contamination, (2) inadequate paint adherence to the test surface, and (3) adverse effects of internal light reflections on data reliability.

Drop in paint sensitivity. Two kinds of contamination of the painted surface were encountered: moisture condensation and occasional bursts of oil mist from the bearing oil system. Water condensation interrupts the testing only temporarily since after evaporation the paint recovers its sensitivity. It is important, however, to watch the live PSP signal for any unusual spots that may indicate the presence of water droplets on the surface because the droplet surface acts as a reflector for the illumination light, thus effectively changing the illumination distribution on the test surface. The oil contamination, on the other hand, is a more serious and permanent problem. Oil does not evaporate and leaves a permanent residue on the painted surface causing a dramatic drop in the PSP signal intensity. The only solution is to interrupt the test, strip the paint, and repaint the surface. Obviously, special care should be exercised to avoid oil leaks into the flow path.

Inadequate adherence to test surface. Two paint erosion problems were observed. First, paint peeling occurred due to high shear stress and severe flow separation at some off-design and transitional operating conditions; second, paint erosion was caused by dust particles in the flow. Fig. 10 contains a photograph showing a stripped vane. To avoid erroneous data, testing should be terminated at the first sign of paint peeling. Even a partially stripped surface (a very small spot) changes the illumination distribution intensity causing a reduction in calibration accuracy. Further, it can generate a false signal (ghost image) that distorts the recorded pressure field. Various primers and undercoating treatments were tried in order to improve the paint adherence under the high shear stresses. For example, buffing the primer before the PSP application appears to improve the paint adherence. A major improvement, however, was achieved by modifying the test procedure. Specifically, tests were started with a reduced total pressure at the fan inlet, with the full inlet pressure being applied only after reaching the particular speed conditions. However, there is little defense 
against erosion due to dust particles in the flow. The air should be filtered whenever possible. Also, developing PSP with increased surface hardness would probably improve the resistance to particle erosion.

Adverse effects of internal light reflections. Internal reflections of the illumination light and the data signal are unavoidable in turbomachinery applications. The high solidity (chord/pitch ratio) blade rows are more prone to light signal reflections due to the narrow blade channels. Walls surrounding the painted surface act as reflectors and in many cases can generate false pressure signals, so called "ghost images" (Lepicovsky et al., 1997). To minimize the signal reflections, PSP should always be applied to only one surface at a time and the other surfaces should be treated with nonreflective paint. Antireflection coatings should be applied to the optical access window.
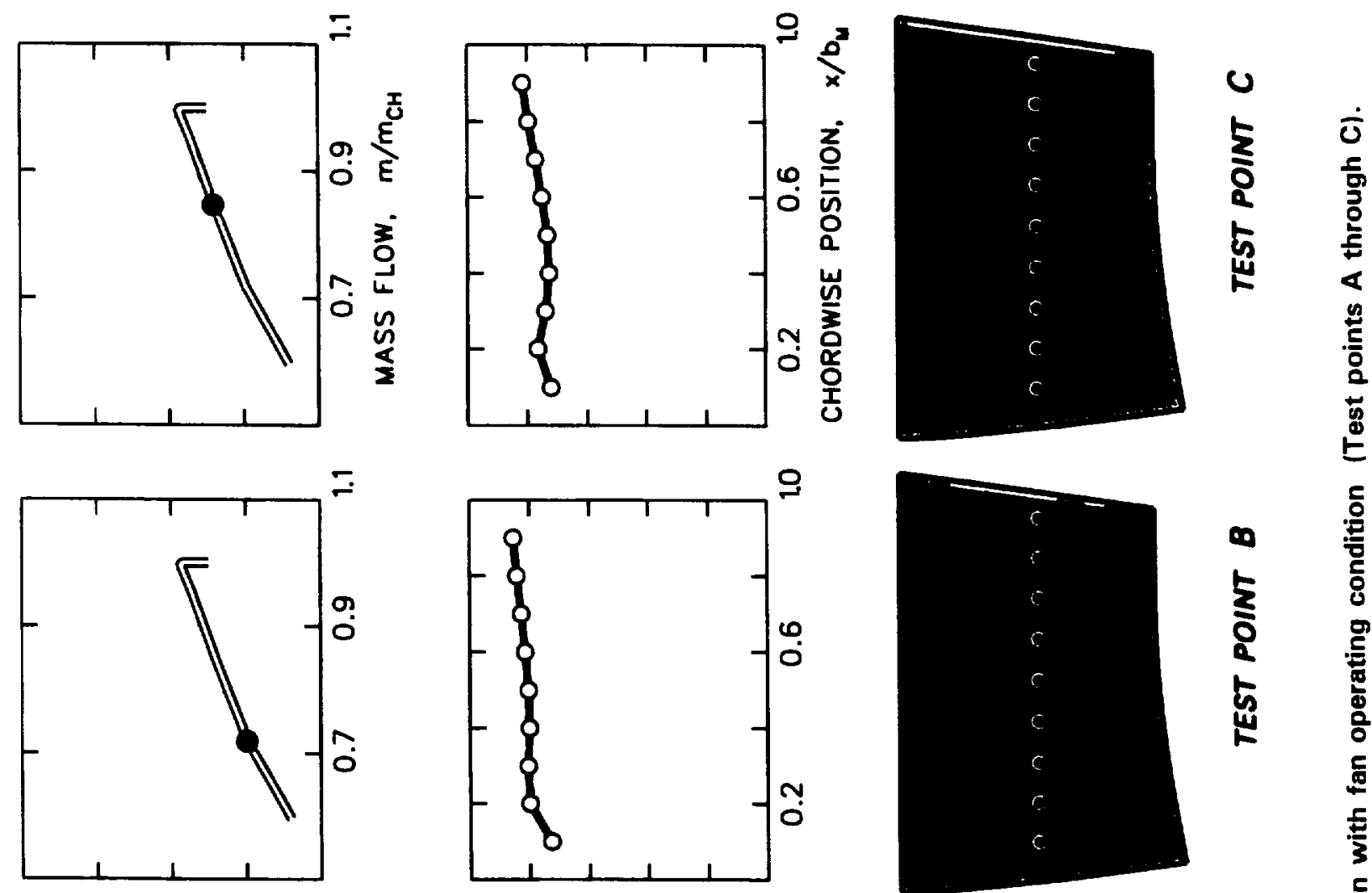

$\infty$
5
0
5
4
5

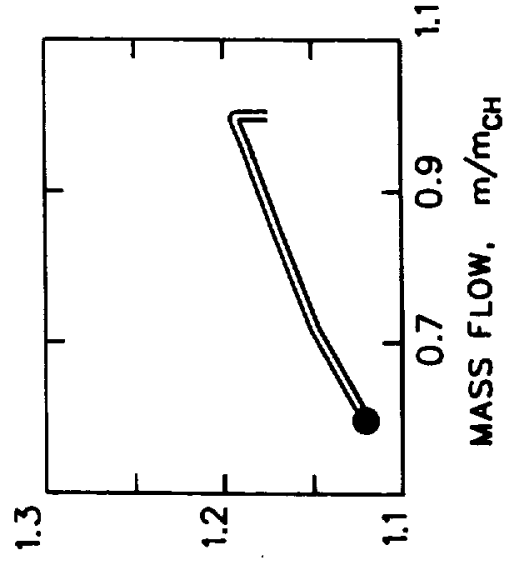

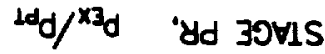

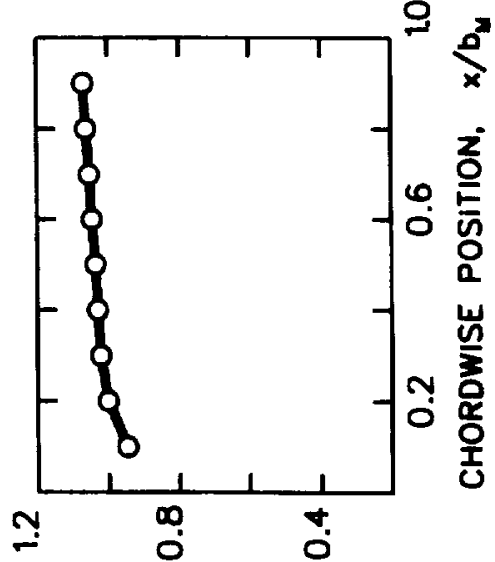

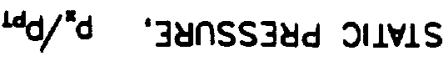

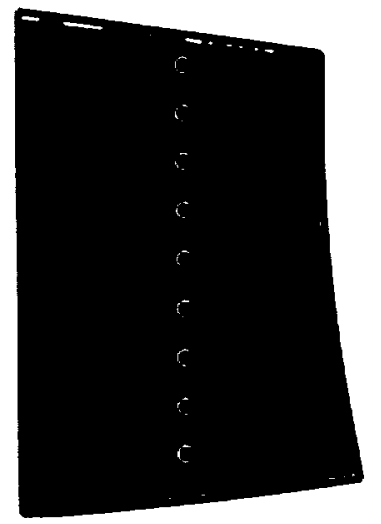

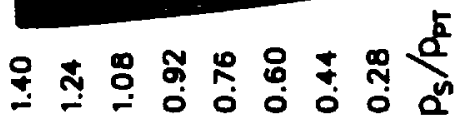
n1118 111118 


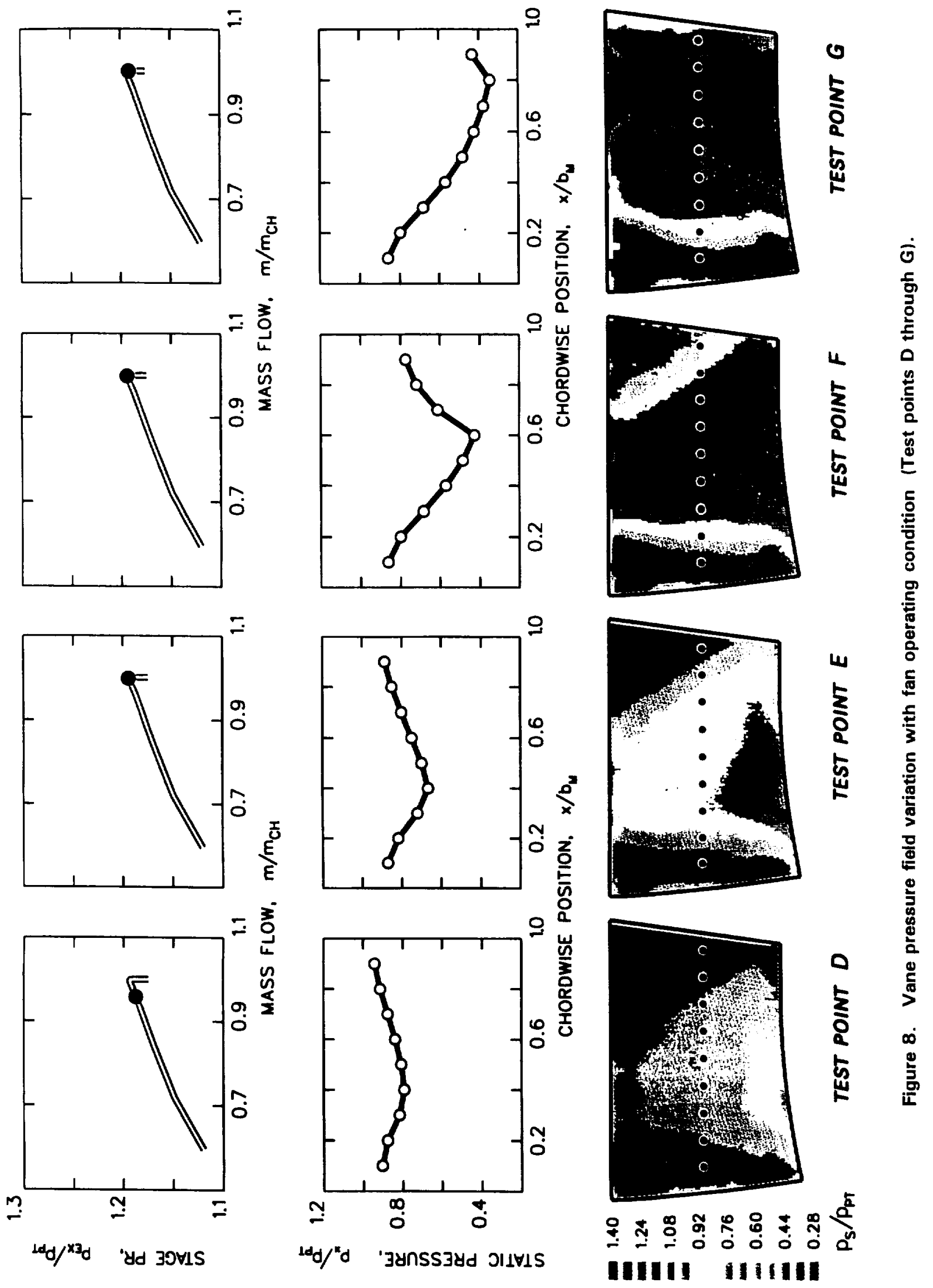




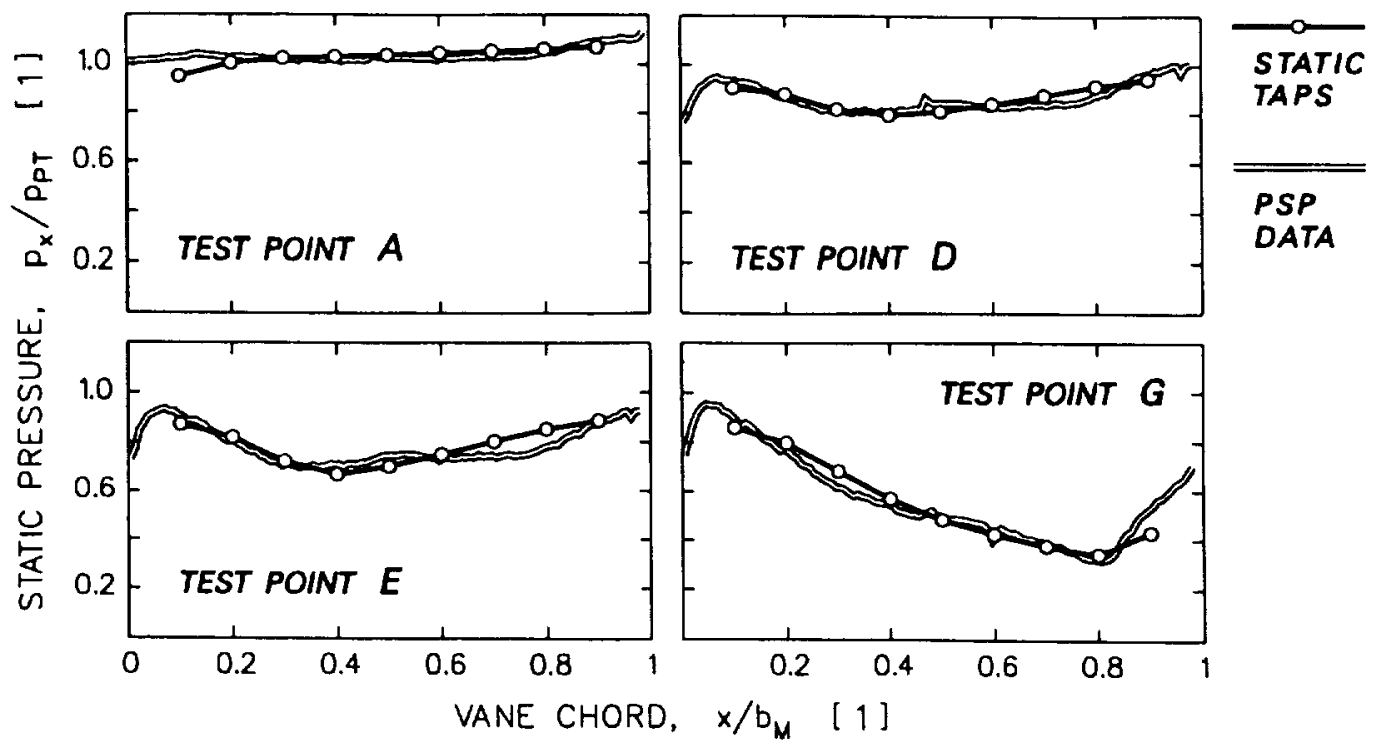

Figure 9. Midspan comparison of static taps and PSP data.

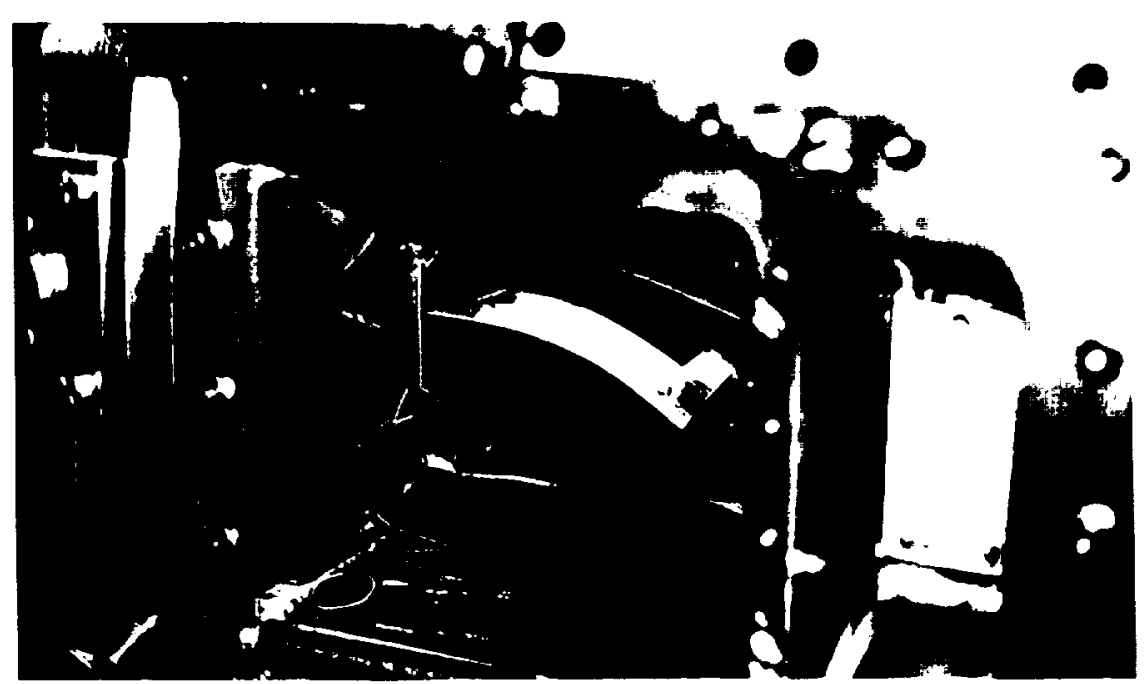

Figure 10. Fully stripped vane suction side.

Solving the problem of internal reflections (ghost images) is critical for succesfully applying the PSP method to turbomachinery and confined flows. There is no single solution for eliminating ghost images and signal contamination in curved narrow channels. The experimenter must be aware of this danger and carefully examine the resulting pressure maps for unusual or unexpected "pressure gradients". Because the position of ghost images depends on the observation angle, changing the camera position can verify whether the unexpected pressure gradients are real or merely signal contamination.

\section{Conclusions}

Valuable experience was gained from applying PSP technique to measurements in a stator channel of a high speed fan. The results show that this nonintrusive experimental technique can work effectively for turbomachinery research. The achieved results indicate the potential of the PSP technique to acquire pressure field data efficiently, particularly for off-design operating conditions where analytical predictions are not always available. On the other hand, the problems encountered show that a lot of work still needs to be done to bring 
the accuracy of the PSP data to the level required for reliable code verification and refinement. The areas that will require special attention are mainly effects of internal reflections and flow temperature on the PSP calibration methodology. Next, the problems of paint erosion and adhesion should be addressed. Finally, suitable changes in test facilities (better optical access ports, flow filtering, and oil leakagel should be considered and implemented for future PSP experiments.

\section{Acknowledgement}

The author is grateful to Dr. L.J. Bober of the NASA LeRC Compressor Branch for his continuing support. T.J. Bencic of NASA LeRC was instrumental in the PSP data acquisition. The help of E.P. Braunscheidel and R.J. Bruckner, both of NASA LeRC, is also particularly acknowledged.

\section{References}

Bencic, T.J., 1995, "Experience Using Pressure Sensitive Paint in NASA Lewis Research Center Propulsion Test Facilities". Paper A/AA 95-2831.

Crites, R.C., 1993, "Pressure Sensitive Paint Technique", VKI Lecture Series, VKILS 1993-05.
Lepicovsky, J., Bruckner, R.J., Bencic, T.J, and Braunscheidel, E.P., 1996, "Modern Experimental Techniques in Turbine Engine Testing", NASA TM107383.

Lepicovsky, J., Bencic, T.J, and, Bruckner, R.J., 1997, "Application of Pressure Sensitive Paint to Confined Flow at Mach Number 2.5", Paper AIAA 97 3214.

Liu, T., Torgerson, S.D., Sullivan, J.P. Johnston, R., and Fleeter, S., 1997, "Rotor Blade Pressure Measurement in a High Speed Axial Compressor Using Pressure and Temperature Sensitive Paints" , Paper A/AA 97-0162.

Morris, M.J., Donovan, J.F., Kegelman, J.T., Schwab, S.D., Levy, R.L., and Crites, R.C., 1992, "Aerodynamic Applications of Pressure-Sensitive Paint", Paper AIAA 92-0264.

Morris, M.J., Benne, M.E., Crites, R.C., and Donovan, J.F., 1993 "Aerodynamic Measurements Based on Photoluminescence", Paper A/AA 93-0175.

Torgerson, S.D., Liu, T., and Sullivan, J.P., 1996, "Use of Pressure Sensitive Paints in Low Speed Flows", Paper AIAA 96-2184.

Woodmansee, M.A. and Dutton, J.C., 1997. "Methods for Treating Temperature-Sensitivity Effects of Pressure-Sensitive Paints", Paper AIAA 97-0387. 


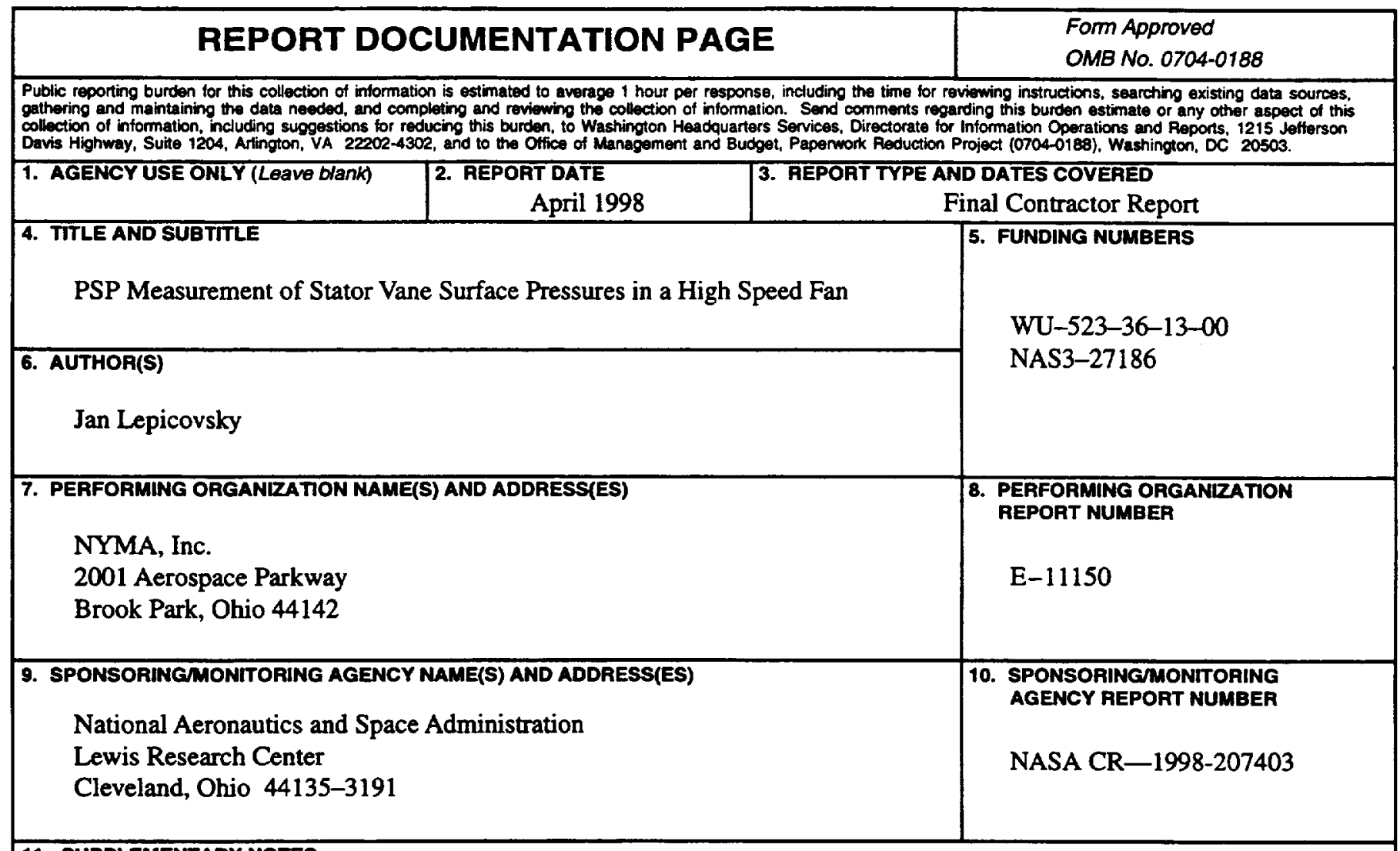

11. SUPPLEMENTARY NOTES

Prepared for the 43rd Gas Turbine and Aeroengine Congress sponsored by the American Society of Mechanical Engineers, Stockholm, Sweden, June 2-5, 1998. Project Manager, Lawrence J. Bober, Turbomachinery and Propulsion Systems Division, NASA Lewis Research Center, organization code 5810, (216) 433-3944.

12a. DISTRIBUTIONAVAILABILITY STATEMENT 12b. DISTRIBUTION CODE

Unclassified - Unlimited

Subject Category: 07

Distribution: Nonstandard

This publication is available from the NASA Center for AeroSpace Information, (301) 621-0390.

13. ABSTRACT (Maximum 200 words)

This paper presents measurements of static pressures on the stator vane suction side of a high-speed single stage fan using the technique of pressure sensitive paint (PSP). The paper illustrates development in application of the relatively new experimental technique to the complex environment of internal flows in turbomachines. First, there is a short explanation of the physics of the PSP technique and a discussion of calibration methods for pressure sensitive paint in the turbomachinery environment. A description of the image conversion process follows. The recorded image of the stator vane pressure field is skewed due to the limited optical access and must be converted to the meridional plane projection for comparison with analytical predictions. The experimental results for seven operating conditions along an off-design rotational speed line are shown in a concise form, including performance map points, midspan static tap pressure distributions, and vane suction side pressure fields. Then, a comparison between static tap and pressure sensitive paint data is discussed. Finally, the paper lists shortcomings of the pressure sensitive paint technology and lessons learned in this highspeed fan application.

14. SUBJECT TERMS

Flow measurements; Turbomachinery; Surface pressures

\begin{tabular}{|c|c|}
\hline $\begin{array}{c}\text { 17. SECURITY CLASSIFICATION } \\
\text { OF REPORT } \\
\text { Unclassified }\end{array}$ & $\begin{array}{c}\text { 18. SECUAITY CLASSIFICATION } \\
\text { OF THIS PAGE } \\
\text { Unclassified }\end{array}$ \\
\hline
\end{tabular}

19. SECURTY CLASSIFICATION
OF ABSTRACT
Unclassified
19. SECURITY CLASSIFICATION Unclassified

20. LIMITATION OF ABSTRACT

